\title{
Precipitation of Secondary Phases in Lean Duplex Stainless Steel 2101 during Isothermal Ageing
}

\author{
Y. L. FANG, ${ }^{1)}$ Z. Y. LIU, ${ }^{1)}$ W. Y. XUE, ${ }^{11}$ H. M. SONG ${ }^{21}$ and L. Z. JIANG ${ }^{21}$ \\ 1) State Key Laboratory of Rolling and Automation, Northeastern University, Shenyang 110004, Liaoning, P. R. China. \\ 2) Research Institute for Stainless Steels, R\&D Center, Baosteel Co., Shanghai, 201900, P. R. China.
}

(Received on September 7, 2009; accepted on November 18, 2009)

\begin{abstract}
In the present paper, the precipitation behavior of secondary phases in Lean Duplex Stainless Steel (LDX) 2101 had been studied. The alloy has a typical ferritic-austenitic duplex structure after solution treatment. Isothermal ageing treatments were carried out over the temperature range from 700 to $850^{\circ} \mathrm{C}$ for the period between 2 min and $1440 \mathrm{~min}$. $\mathrm{Cr}_{2} \mathrm{~N}$-type nitrides were formed as the main product of precipitates, together with small amount of $\mathrm{Cr}_{23} \mathrm{C}_{6}$-type carbides. Increase of $\mathrm{N}$ content and decrease of $\mathrm{Cr}$ and $\mathrm{Mo}$ contents in the steel had led to the absence of $\sigma$-phase. Due to the solid solution strengthening by interstitial atoms, the hardness value of austenite was measured to be higher than that of ferrite. With increasing the isothermal ageing time, precipitates were observed to be preferentially nucleated at the $\delta / \gamma$ interface and grown toward the $\delta$ phase. The $\delta / \gamma$ interfce migrated from the precipitate particles into $\delta$ phase, leaving the precipitates behind along the original interfaces, which could increase the size of the secondary austenite $\left(\gamma^{\prime}\right)$ phase and decrease the hardness of both austenite and ferrite. Inside $\gamma^{\prime}$ phase, the hardness was measured to increase from about 3.20 GPa at the original interface to about 3.75 GPa at the newly formed interface of $\delta / \gamma^{\prime}$. The isothermal kinetics for the precipitation of secondary phases was measured to obey the JMAK-type law. The TTT (time-temperature-transformation) curve was constructed based on the measurements, which seems to have resulted from the overlap of two different precipitated products. The average impact energy at room temperature for the sample after solid solution treatment was measured to be $105 \mathrm{~J}$. When $2 \%$ secondary phases were precipitated during ageing, the impact energy decreased to about $43 \mathrm{~J}$, reduced by about $59 \%$ as compared with the as-annealed sample, indicating that formation of secondary phases can result in dramatic decrease of steel toughness.
\end{abstract}

KEY WORDS: duplex stainless steel; isothermal ageing treatment; secondary phases; microstructure; impact toughness.

\section{Introduction}

Duplex stainless steels (DSSs) are processed to have a balanced microstructure containing approximately equal amounts of ferrite and austenite, which exhibits exceptional mechanical properties and corrosion resistance. ${ }^{1,2)}$ Lean Duplex Stainless Steel (LDX) 2101 with lower contents of $\mathrm{Ni}$ and Mo had been developed in order to further reduce and stabilize the cost. ${ }^{3)}$

Complex precipitation often occurs in DSSs because of high contents of alloying elements. ${ }^{4}$ A considerable number of studies on the intermetallic phase transformation behaviour such as $\sigma$ and $\chi$ phases in association with mechanical properties of DSSs had been performed. ${ }^{5-9)}$ Chen and co-workers studied the relationship among microstructure, hardness and toughness of 2205 duplex stainless steel. ${ }^{10)} \mathrm{Kim}$ and co-workers investigated the isothermal formation behavior of secondary phases and employed an Avrami analysis to assess transformation characteristics. ${ }^{112)}$ Huang and co-workers found that more nitrogen content in DSSs could lead to lower content of $\sigma$-phase. ${ }^{13)}$

Due to the increased use of nitrogen, the precipitation of
$\mathrm{Cr}_{2} \mathrm{~N}$-type nitrides increased significantly in the temperature range from $700^{\circ} \mathrm{C}$ to $900^{\circ} \mathrm{C}^{6)}$ Zhang ${ }^{14)}$ studied the effect of ageing on precipitation and impact energy of LDX 2101 and found that the most sensitive embrittlement temperature was about $700^{\circ} \mathrm{C}$, and formation of nitrides was the main reason for the decrease of impact energy. Similar results were obtained by Charles ${ }^{15)}$ and Liljas, ${ }^{16)}$ indicating that nitride precipitation severely impaired the corrosion resistance and the toughness of the DSSs. Despite these studies on the precipitation in LDX $2101,{ }^{14-16)}$ the microstructure evolution and mechanical properties have not been thoroughly clarified and still need to be further investigated.

In the present paper, isothermal ageing treatments were carried out to elucidate the precipitation behavior. Particular attention was paid to both the observation of microstructure evolution and measurement of hardness and toughness for the steel aged in the temperature range of $700-850^{\circ} \mathrm{C}$.

\section{Experimental Procedures}

The DSS ingot was made by standard vacuum melting and casting, which possessed duplex ferritic-austenitic mi- 
crostructures. Table 1 shows the chemical composition of the alloy. The ingot was reheated for $3 \mathrm{~h}$ to be homogenized, and was hot rolled to $8 \mathrm{~mm}$ thick bands by 10 passes. Samples with dimensions of $10 \mathrm{~mm}$ in length, $10 \mathrm{~mm}$ in width and $8 \mathrm{~mm}$ in thickness were used in the solution treatment, which was performed at $1100^{\circ} \mathrm{C}$ for $30 \mathrm{~min}$ followed by water quenching for complete dissolution of secondary phases and microstructure homogenization. Isothermal ageing treatments were carried out over the temperature range from 700 to $850^{\circ} \mathrm{C}$ for periods of time between 2 and $1440 \mathrm{~min}$.

Optical microscope (OM), scanning electron microscope (SEM) and transmission electron microscopy (TEM) were used to characterize the microstructure of the samples. Before metallographic observation, samples were electro-polished in the solution of $50 \mathrm{~mL} \mathrm{HClO}_{4}+650 \mathrm{~mL} \mathrm{C}_{2} \mathrm{H}_{5} \mathrm{OH}+$ $100 \mathrm{~mL} \mathrm{H}_{2} \mathrm{O}$ at the voltage of $20-35 \mathrm{~V}$ for $10-50 \mathrm{~s}$, in which austenite, secondary austenite, ferrite and precipitates could be distinguished. The samples were also etched by using the reagent of $4 \mathrm{~g} \mathrm{KMnO}_{4}+4 \mathrm{~g} \mathrm{NaOH}+100 \mathrm{~mL}$ $\mathrm{H}_{2} \mathrm{O}$ at $60-90^{\circ} \mathrm{C}$ for $1-10 \mathrm{~min}$, in which austenite and ferrite were not affected and precipitates were tinted to be black for precise measurements of the precipitated fractions. 20 fields for each sample were measured by using an image analysis system. Foils for TEM observation were prepared by jet polishing in the solution of $91 \mathrm{vol}$ pct alcohol and 9 vol pet perchloric acid at $-20^{\circ} \mathrm{C}$ with the voltage of $30 \mathrm{~V}$.

The samples for nano-indentation tests were electro-polished. In the nano-indentation tests, a Berkovich tip was used as an indenter to evaluate the hardness of ferrite $(\delta)$, austenite $(\gamma)$ and secondary austenite $\left(\gamma^{\prime}\right)$ phases with the indentation load of $1000 \mu \mathrm{N}$.

The Charpy V-notch impact tests were carried out at ambient temperature. The samples were machined from both the as-annealed and as-aged plates along the rolling direction with standard dimensions of $55 \mathrm{~mm}$ in length, $10 \mathrm{~mm}$ in width and $5 \mathrm{~mm}$ in thickness.

Table 1. Chemical composition of the LDX 2101, wt $\%$

\begin{tabular}{cccccccccc}
\hline $\mathrm{C}$ & $\mathrm{Si}$ & $\mathrm{Mn}$ & $\mathrm{P}$ & $\mathrm{S}$ & $\mathrm{Cr}$ & $\mathrm{Mo}$ & $\mathrm{Ni}$ & $\mathrm{N}$ & $\mathrm{Cu}$ \\
\hline 0.026 & 0.28 & 5.3 & 0.017 & 0.004 & 21.2 & 0.31 & 1.5 & 0.22 & 0.28 \\
\hline
\end{tabular}

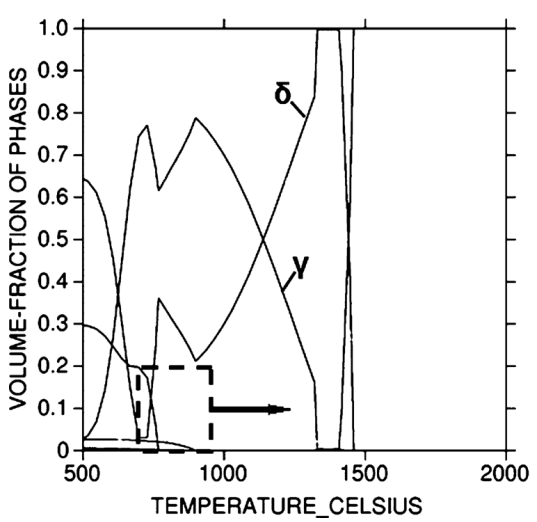

\section{Results}

Figure 1 shows the equilibrium phase diagram calculated by using the Thermo-Calc software for the experimental LDX 2101, which indicates that only $\delta$-ferrite and $\gamma$ austenite are formed above $900^{\circ} \mathrm{C}$. Ferrite and austenite contents are almost equivalent in the temperature range between 1100 and $1150^{\circ} \mathrm{C}$. At temperatures below $900^{\circ} \mathrm{C}$, secondary phases start to precipitate, and nitride, carbide and intermetallic $\sigma$-phase are thermodynamically possible to be formed, with the starting temperatures for the formations of nitride, carbide and $\sigma$-phase being about $900^{\circ} \mathrm{C}$, $820^{\circ} \mathrm{C}$ and $770^{\circ} \mathrm{C}$, respectively.

Figures 2 shows the microstructure of the as-annealed sample after the solution treatments at $1100^{\circ} \mathrm{C}$ for $30 \mathrm{~min}$, which is consisted of almost equivalent volume fractions of ferrite and austenite. Austenite grains (light) are embedded in the ferrite matrix (grey), with no indication of any precipitates after the solution treatment. By using the nano-indenter, the nano-mechanical properties have been measured for the typical austenite and ferrite grains after the solution treatment. Figures 3(a) and 3(b) show the image of the microstructure and the load-depth relationships for different phases, respectively. It can be seen that the nano-hardness values of ferrite and austenite were measured to be 4.03 and $5.09 \mathrm{GPa}$, respectively.

Figures 4 show the optical micrographs of the microstructures formed during isothermal ageing at $800^{\circ} \mathrm{C}$ for different times. For the samples after the ageing treatment

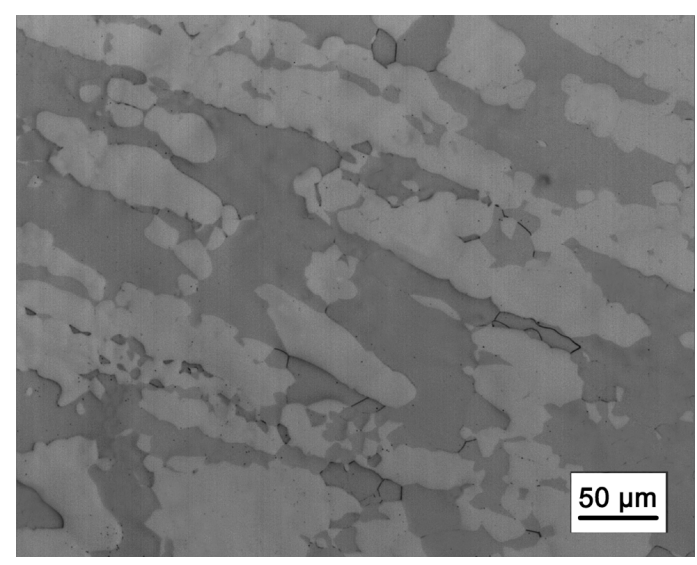

Fig. 2. Optical micrographs for the microstructure of LDX 2101 solid solution treatments at $1100^{\circ} \mathrm{C}$ for $30 \mathrm{~min}$.

Fig. 1. The equilibrium phase diagram calculated by using the Thermo-Calc software for LDX 2101 . 

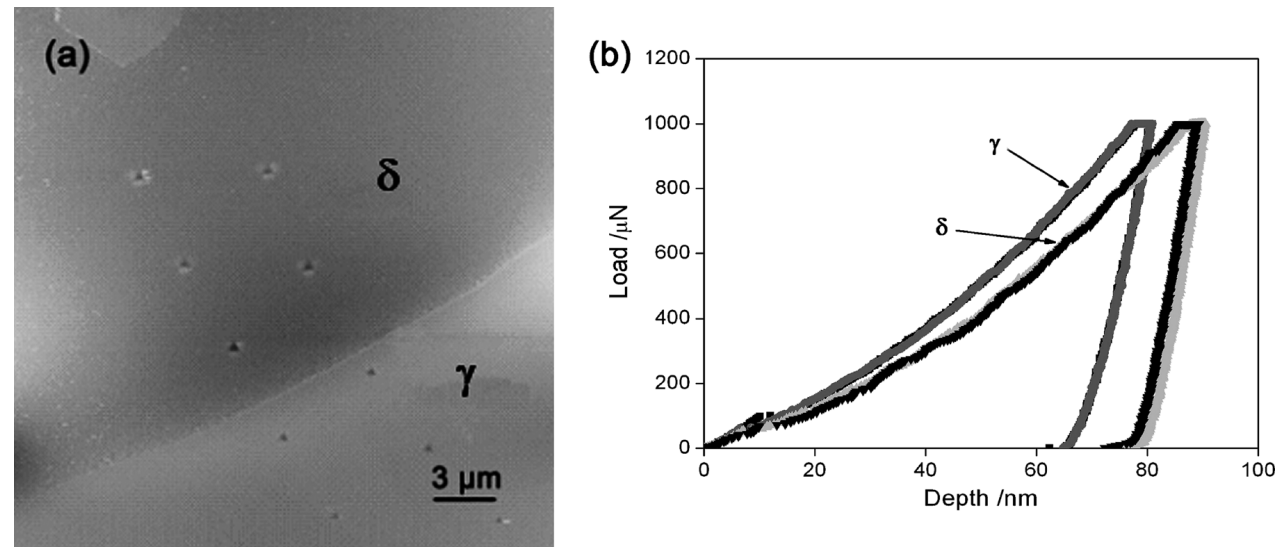

Fig. 3. (a) The scanning image of the microstructure; (b) typical load-depth curves for austenite and ferrite phases obtained after solid solution treatments at $1100^{\circ} \mathrm{C}$ for $30 \mathrm{~min}$.
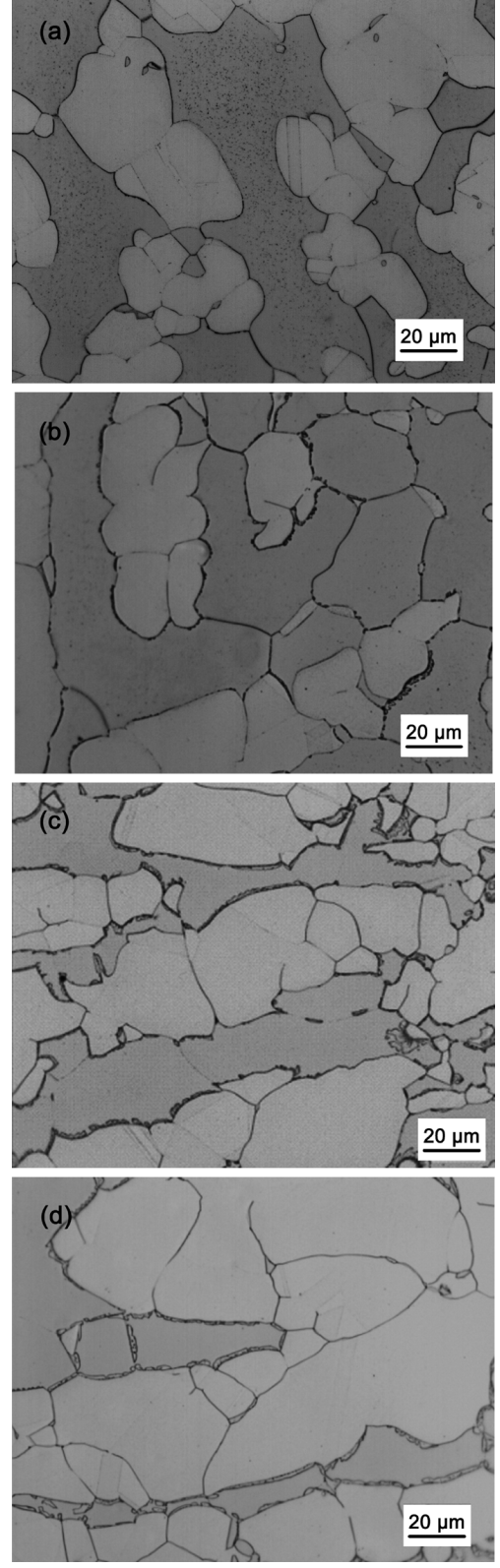

Fig. 4. Optical micrographs for the microstructures formed during isothermal ageing at $800^{\circ} \mathrm{C}$ for different times; (a) $2 \mathrm{~min}$; (b) $10 \mathrm{~min}$; (c) $30 \mathrm{~min}$; (4) $1440 \mathrm{~min}$.

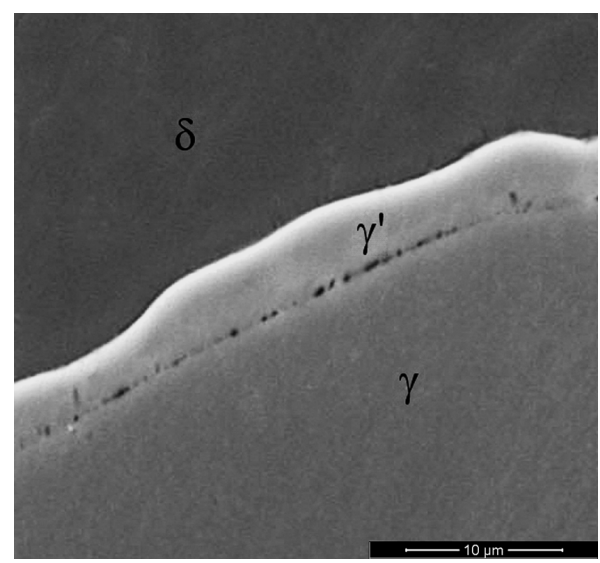

Fig. 5. SEM micrograph for the microstrucutre after isothermal ageing at $800^{\circ} \mathrm{C}$ for $1440 \mathrm{~min}$.

for 2 min, Fig. 4(a), tiny precipitates were formed at the interfaces between austenite island and ferrite matrix $(\delta / \gamma)$, grain boundaries of ferrite matrix $(\delta / \delta)$ and in the $\delta$ phase interiors. For the samples after the ageing treatment for 10 min, Fig. 4(b), the size and amount of precipitates increased. Nitrides formed along the $\delta / \gamma$ interface grew toward ferrite, and the secondary austenite surrounding precipitates started to form. Figures 4(c) and 4(d) show the optical micrographs of the samples after the isothermal ageing for $30 \mathrm{~min}$ and $1440 \mathrm{~min}$, respectively. They clearly reveal that the $\delta / \gamma$ interface has moved away from the precipitate particles, grown into the $\delta$ phase, leaving the precipitates behind along the original interfaces. Figure 5 shows the SEM micrograph for the microstructure after the isothermal ageing at $800^{\circ} \mathrm{C}$ for $1440 \mathrm{~min}$. It can be seen that the precipitates formed inside the $\delta$ grains at the early stage of isothermal ageing had been dissolved.

Figure 6(a) shows the scanning image of the microstructure after the isothermal ageing at $800^{\circ} \mathrm{C}$ for $1440 \mathrm{~min}$. Figure 6(b) shows the nano-hardness variation at different positions among ferrite, austenite and secondary austenite. The nano-hardness values for ferrite and austenite were measured to be 3.48 and $4.02 \mathrm{GPa}$, respectively. The nanohardness in secondary austenite was measured to increase from $3.20 \mathrm{GPa}$ at the original interface to $3.75 \mathrm{GPa}$ at the newly fromed interface of $\delta / \gamma^{\prime}$.

Figures 7 show the microstructures formed after the 

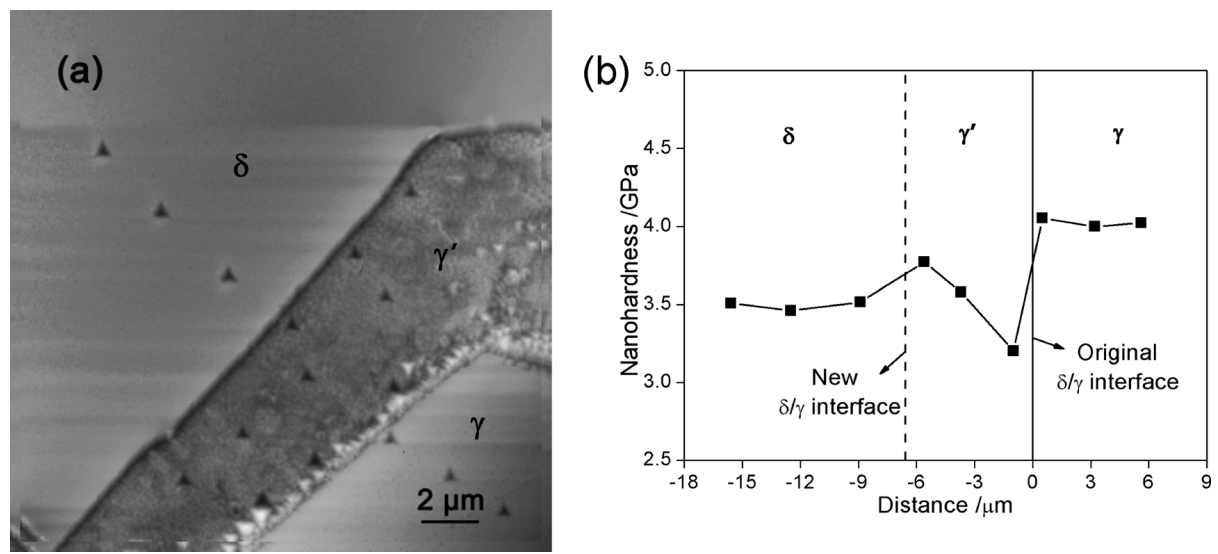

Fig. 6. (a) The scanning image of the microstructure; (b) nano-hardness variation at different positions among ferrite, austenite and secondary austeniteafter isothermal ageing at $800^{\circ} \mathrm{C}$ for $1440 \mathrm{~min}$.
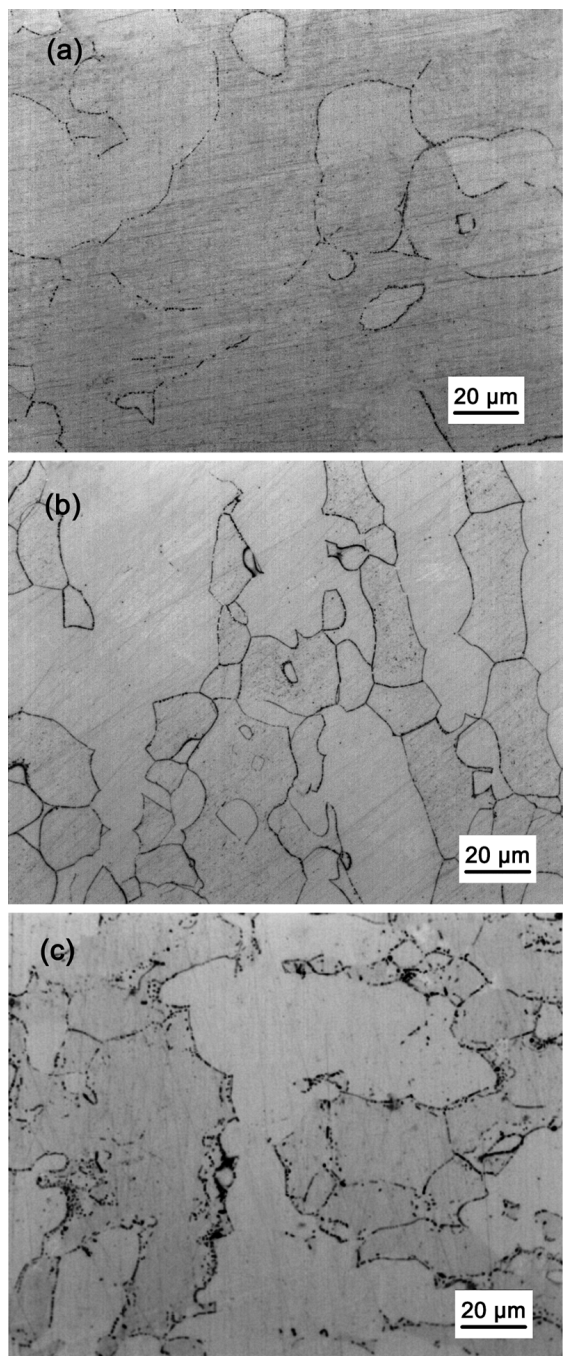

Fig. 7. Optical micrographs for the microstructures formed during isothermal ageing at $700^{\circ} \mathrm{C}$ for different times etched with $4 \mathrm{~g} \mathrm{KMnO}_{4}+4 \mathrm{~mL} \mathrm{HCl}+4 \mathrm{~mL} \mathrm{H}_{2} \mathrm{O}$ solution; (a) $2 \mathrm{~min}$; (b) $30 \mathrm{~min}$; (c) $1440 \mathrm{~min}$.

isothermal ageing at $700^{\circ} \mathrm{C}$ for different times, which were etched by the regent of $4 \mathrm{~g} \mathrm{KMnO}_{4}+4 \mathrm{~mL} \mathrm{HCl}+4 \mathrm{~mL} \mathrm{H}_{2} \mathrm{O}$ in order to measure the volume fraction of precipitates more accurately. Figure 8(a) shows the relationship between the measured volume fractions of precipitates and the holding time in the range of temperatures from 700 to
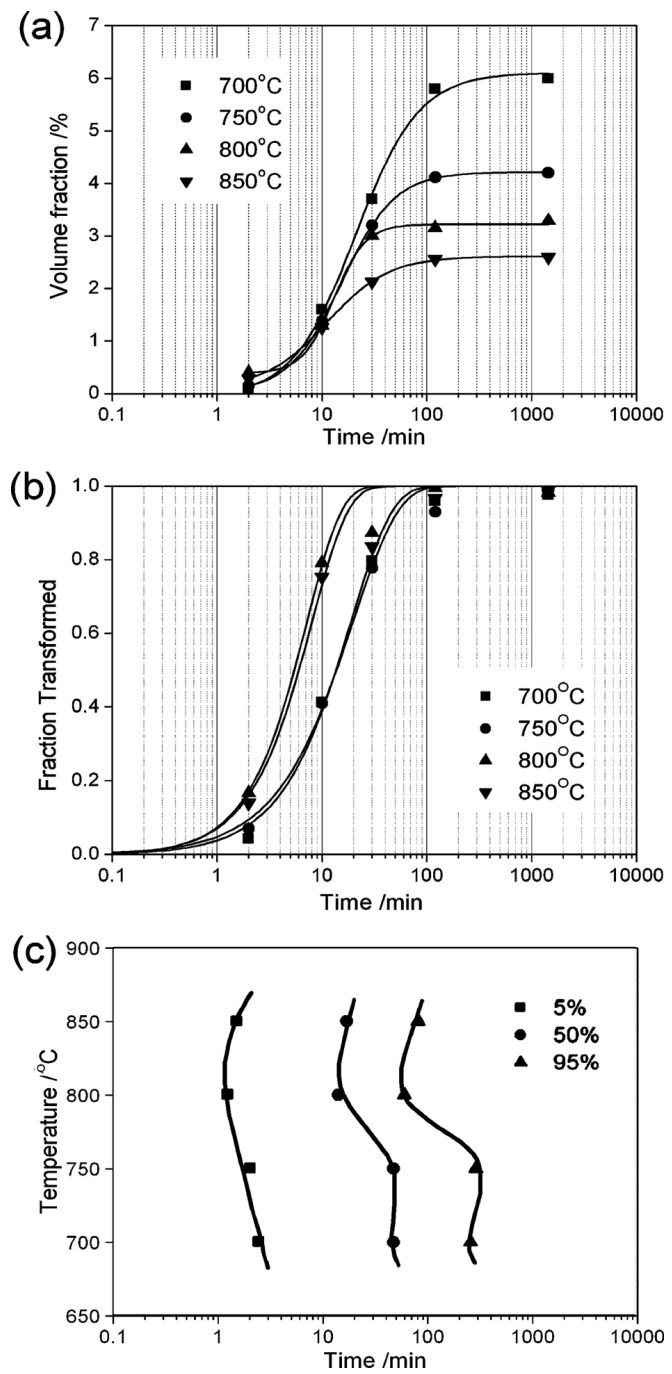

Fig. 8. (a) The relationship between volume fraction of precipitates and the holding time; (b) JMAK curves; (c) the calculated time-temperature-transformation (TTT) curves determined for LDX 2101 over the temperature range from 700 to $850^{\circ} \mathrm{C}$.

$850^{\circ} \mathrm{C}$. It can be seen that the fraction increases with decreasing the isothermal holding temperature. By using the Johnson-Mehl-Avrami-Kolmogrov (JMAK) method, ${ }^{12,17)}$ the precipitation kinetics can be obtained as Eq. (1): 
Table 2. JMAK parameters determined for the LDX 2101.

\begin{tabular}{ccc}
\hline Temperature $/{ }^{\circ} \mathrm{C}$ & $\mathrm{k} / \mathrm{min}^{-1}$ & $\mathrm{n}$ \\
\hline 700 & 0.03909 & 1.10152 \\
750 & 0.04944 & 1.00714 \\
800 & 0.07605 & 1.30621 \\
850 & 0.07336 & 1.25317 \\
\hline
\end{tabular}
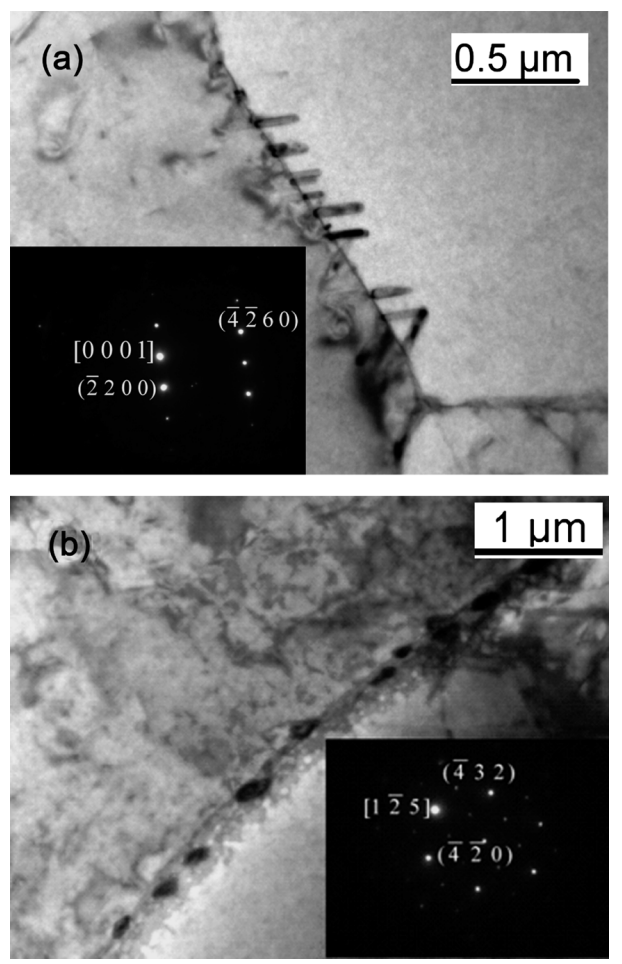

Fig. 9. TEM photos and the corresponding selected area diffraction patterns; (a) $\mathrm{Cr}_{2} \mathrm{~N}$, isothermal aged at $800^{\circ} \mathrm{C}$ for $30 \mathrm{~min}$; (b) $\mathrm{Cr}_{23} \mathrm{C}_{6}$, isothermal aged at $700^{\circ} \mathrm{C}$ for $30 \mathrm{~min}$.

$$
f_{e}(t)=\frac{V}{V_{\max }}=1-\exp \left(-k t^{n}\right)
$$

where, $f_{e}(t)$ is the transformed fraction, $k$ the constant, and the exponent $n$ the dimensionless constant that depends on the combination of nucleation and growth mechanisms for the precipitation process. In order to obtain the transformed fraction $\left(f_{e}(t)\right)$, it is necessary to find the maximum volume fractions of precipitates $\left(V_{\text {max }}\right)$. Figure 8(a) shows that the volume fraction of precipitates leveled off after isothermal ageing for $1440 \mathrm{~min}$, which was determined to be $V_{\max }$. The corresponding JMAK curves and calculated $n$ and $k$ values are shown in Figure 8(b) and Table 2, respectively. Figure 8(c) shows the time-temperature-transformation (TTT) curves developed by using Eq. (1), with 5, 50 and 95\% transformed fraction having been plotted.

Figure 9 show TEM micrographs of the precipitates with corresponding selected-area diffraction patterns (SADP). Most precipitates in this alloy were fine $\mathrm{Cr}_{2} \mathrm{~N}$ nitrides. Its crystal structure was found to be hexagonal with lattice parameters of $a=0.481 \mathrm{~nm}$ and $c=0.448 \mathrm{~nm}$ based on the SADP from the $\left[\begin{array}{llll}0 & 0 & 0 & 1\end{array}\right]$ zone axis, Fig. 9(a). Except for nitrides, small amount of $\mathrm{Cr}_{23} \mathrm{C}_{6}$-type carbide (cubic crystal structure with lattice parameter of $a=1.056 \mathrm{~nm}$ ) was also detected after the isothermal ageing at relatively lower tem-
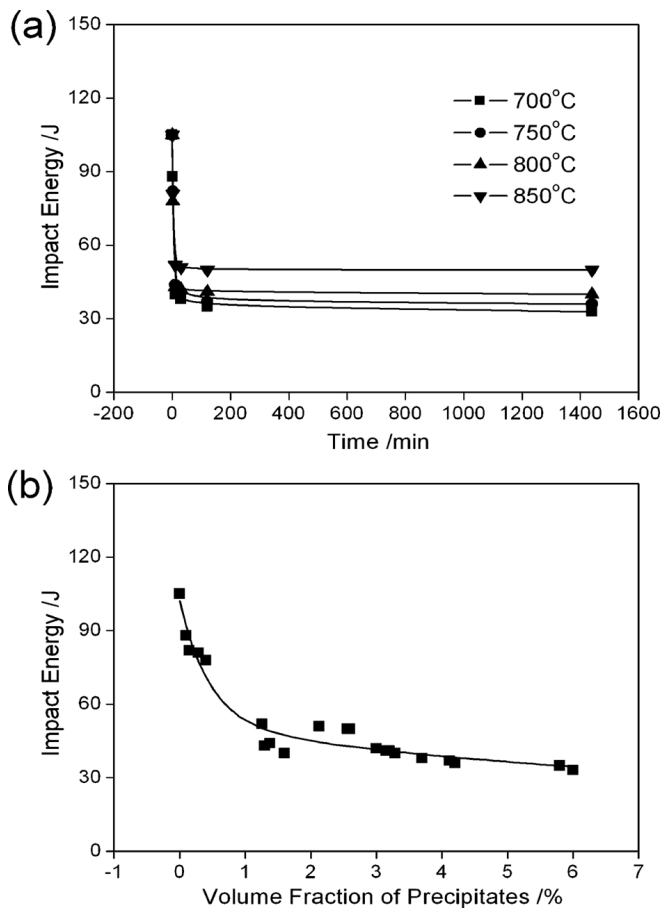

Fig. 10. (a) The relationship between the impact energy for the samples after isothermal ageing times at different temperatures; (b) the relationship between impact energy at room temperature and volume fraction of precipitates.

peratures, Fig. 9(b). The $\sigma$-phase was not detected even after isothermal ageing for $1440 \mathrm{~min}$.

Figure 10(a) shows the relationship between impact energy and isothermal ageing times for different temperatures. It can be seen that the impact energy decreased rapidly with increasing the isothermal ageing time. When ageing times increased to $120 \mathrm{~min}$, the impact energy almost decreased to the minimum value. At $700^{\circ} \mathrm{C}$, the sample exhibited the average impact energy of $33 \mathrm{~J}$, which can be determined to be the most sensitive embrittlement temperature. Figure 10(b) shows the relationship between impact energy and volume fractions of precipitates. The average impact energy of the as-annealed sample was measured to be $105 \mathrm{~J}$. With the precipitation volume fraction of about $2 \%$, the impact energy was measured to be about $43 \mathrm{~J}$, reduced by more than $59 \%$ as compared to as-annealed sample, indicating that drastic decrease of impact energy can occur by forming small amount of precipitates.

Figure 11(a) shows the fracture morphology of the asannealed sample, which consisted of a large number of dimples. Inclusions such as aluminium oxide and manganese sulfide were found to be associated with these dimples. Figure 11(b) shows the fracture morphology of the sample having been aged at $700^{\circ} \mathrm{C}$ for $120 \mathrm{~min}$. By contrast, it exhibited the fracture morphology with intra-granular facets in a river-like pattern. Micro-voids in the size of about $0.5 \mu \mathrm{m}$, as indicated by the arrows, were formed due to the presence of precipitate particles dispersed in facets.

\section{Discussion}

The Thermo-calc calculation has predicted that the consumption of $\delta$-ferrite could lead to the formation of $\sigma$ phase precipitation. In the present work, however, $\sigma$-phase 

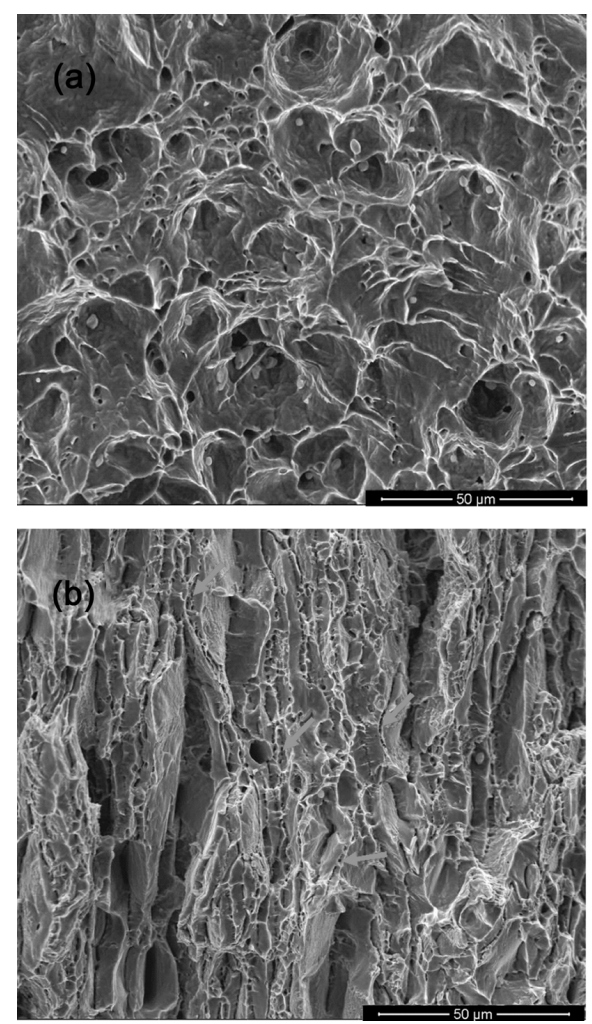

Fig. 11. Fractographic investigation conducted on the fractured surfaces (a) as-annealed condition; (b) aged at $700^{\circ} \mathrm{C}$ for $120 \mathrm{~min}$.

could not be observed at all, and the volume fraction of $\delta$ ferrite slightly decreased, inconsistent with the thermodynamic calculation results, but in good agreements with the results by Zhang, ${ }^{14)}$ Toor, ${ }^{18)}$ and Calliari, ${ }^{19)}$ who confirmed the absence of $\sigma$-phase precipitation in the steels with similar compositions. The $\sigma$-phase is enriched with $\mathrm{Cr}$ and $\mathrm{Mo}$, and diffusion of $\mathrm{Cr}$ and $\mathrm{Mo}$ is usually regarded as the main controlling factor for its formation. ${ }^{20)}$ As compared to conventional DSSs, ${ }^{5-13)}$ the contents of $\mathrm{Cr}$ and Mo in LDX 2101 are reduced. Also, high nitrogen content in LDX 2101 could retard or even prevent the formation of $\sigma$-phase. ${ }^{16,21)}$ Therefore, increase of $\mathrm{N}$ content and decrease of $\mathrm{Cr}$ and Mo contents can lead to the absence of $\sigma$-phase formation.

The precipitates formed in LDX 2101 after isothermal ageing in the temperature range from 700 to $850^{\circ} \mathrm{C}$ were comprised of large amount of nitrides and small amount of carbides. In ferritic and austenitic steels, carbon significantly segregates along grain boundaries, while the segregation of nitrogen along grain boundaries is not obvious. ${ }^{223)}$ Therefore, during isothermal ageing treatments, precipitation of chromium nitride along grain boundaries can be suppressed as compared to the precipitation of chromium carbides. With increasing nitrogen content, the formation of $\mathrm{Cr}_{23} \mathrm{C}_{6}$-type carbides can be retarded because the substitution of small amount of nitrogen in $\mathrm{Cr}_{23} \mathrm{C}_{6}$ could result in its complete dissolution, ${ }^{24)}$ causing the amount of $\mathrm{Cr}_{2} \mathrm{~N}$-type nitrides to be significantly increased. ${ }^{25,26)}$ In the present work, the atomic ratio of nitrogen to carbon is 8.46 , which should be enough for the promotion of the nitride precipitation relative to carbides.

The interfaces between austenite islands and ferrite matrix and ferrite grain boundaries have been believed to be
Table 3. The chemical composition of ferrite $(\delta)$, austenite $(\gamma)$ and secondary austenite $\left(\gamma^{\prime}\right)$ for the samples aged at $800^{\circ} \mathrm{C}$ for $30 \mathrm{~min}$.

\begin{tabular}{ccccc}
\hline Element & $\mathrm{Cr}$ & $\mathrm{Mn}$ & $\mathrm{Fe}$ & $\mathrm{Ni}$ \\
\hline$\delta$ & 24.91 & 4.57 & 66.11 & 1.33 \\
$\mathrm{Y}$ & 20.20 & 5.83 & 68.01 & 2.98 \\
$\mathrm{Y}^{\prime}$ & 17.03 & 7.49 & 69.55 & 3.12 \\
\hline
\end{tabular}

the preferential nucleation sites for heterogeneous precipitation of $\mathrm{Cr}_{2} \mathrm{~N}$-type nitrides and $\mathrm{Cr}_{23} \mathrm{C}_{6}$-type carbides. ${ }^{27-29)}$ During isothermal ageing, the precipitation processes of inter-granular nitrides and carbides were similar, with the transformation of $\delta \rightarrow \gamma^{\prime}+\mathrm{Cr}_{2} \mathrm{~N} / \mathrm{Cr}_{23} \mathrm{C}_{6}$. Nitrides or carbides were the leading precipitation phases preferentially nucleated at the $\delta / \gamma$ interfaces. ${ }^{28,30)}$ With increasing isothermal ageing time, the precipitates grew toward the ferrite phase, resulting in local $\mathrm{Cr}$ depletion or $\mathrm{Ni}$ and $\mathrm{Mn}$ local enrichment around these precipitates, which could promote the precipitation of $\gamma^{\prime}$ phase. Table 3 shows the chemical compositions of ferrite, austenite and secondary austenite $\left(\gamma^{\prime}\right)$, showing the supporting evidence for the formation mechanism of $\gamma^{\prime}$ phase. With the growth of $\gamma^{\prime}$ phase during isothermal ageing, more $\mathrm{Cr}$ atoms could be ejected to its adjacent ferrite. The nitride, therefore, could be formed in this region due to the high diffusivity of nitrogen in ferrite. $^{28,31)}$

Previous work ${ }^{28,32,33)}$ reported that dominant intra-granular precipitates were observed to be nitrides in DSSs. Intragranular nitrides could be formed in ferrite during quenching from solution temperatures and isothermal ageing treatments at relatively low temperatures. ${ }^{33)}$ In the present work, however, the formation of chromium nitrides was only observed during isothermal ageing treatments, but not during quenching from solution annealing temperatures. Intragranular nitrides in ferrite was not stable and could easily be dissolved when having been aged for longer times. ${ }^{28)}$ Due to low solubility and high diffusivity of nitrogen in ferrite, the dissolution of intra-granular nitrides within ferrite could provide enough nitrogen for the nucleation and growth of inter-granular nitrides.

In the present work, the nano-hardness of austenite was measured to be obviously higher than that of ferrite after the solution treatments at $1100^{\circ} \mathrm{C}$ for $30 \mathrm{~min}$, Fig. 3 . In duplex stainless steels, austenite has been believed to be a soft phase and the strength was enhanced by increasing the amount of ferrite. ${ }^{34,35)}$ However, nitrogen in DSS mainly dissolved in austenite due to its high solubility of about $0.45 \mathrm{wt} \%$ in the face-centered-cubic (fcc) lattice. ${ }^{16)}$ Indeed, the effect of the nitrogen content on the strength of austenite is quite important. Therefore, the austenite can become stronger phase due to the interstitial solid solution strengthening when the nitrogen content in the steel is higher than $0.2 \%{ }^{36)}$

After isothermal ageing at $800^{\circ} \mathrm{C}$ for $1440 \mathrm{~min}$, the nano-hardness of ferrite and austenite were measured to be 3.48 and $4.02 \mathrm{GPa}$ respectively, Fig. 6, which were lower than those after the solution treatments. In the formation of precipitates, interstitial atoms may have transported from austenite or ferrite by long-range diffusion to meet $\mathrm{Cr}$ and $\mathrm{Ni}$ to form the precipitates, which will consume some intersitial atoms in the original austenite and ferrite. The effect 
of interstitial atoms on strength and hardness is more prominent than substitution atoms. Therefore, the nanohardness of both austenite and ferrite has been decreased after the isothermal ageing for relatively long time, which is in agreement with the results reported by Vanderschaeve ${ }^{37)}$ and Yuan. ${ }^{38)}$

With increasing the isothermal ageing time, the $\delta / \gamma$ interface migration had increased the size of the secondary austenite, which was big enough for the measurement of its nano-hardness. Although the lattice parameter of the secondary austenite was similar with that of austenite, inhomogeneous distribution of interstitial atoms in the secondary austenite may lead to different nano-hardness values. The formation of secondary austenite and nitrides/carbides is diffusion dependent, which generate obvious concentration gradient of interstitial atoms from the original $\delta / \gamma$ interface to the newly formed interface. In the vicinity of the precipitates, the secondary austenite was measured to be $3.20 \mathrm{GPa}$; by contrast, at the newly formed interface, the hardness was measured to be about $3.75 \mathrm{GPa}$, indicating that concentration of interstitial atoms increased away from the original $\delta / \gamma$ interface.

Although the JMAK exponent, $n$, can not be used to precisely identify the precipitation mechanism, it can be used as a simple indicator for the nucleation and growth of precipitates. ${ }^{39)}$ The $\mathrm{n}$ values have been calculated to be from 1.01 to 1.31 , indicating that the growth of needle and/or plate-like precipitates with finite long dimensions has been controlled by diffusion. ${ }^{17)}$ As a result, even after long time of isothermal holding, the precipitates could retain their original shapes and never exceeded the size of about $1 \mathrm{~mm}$.

Figure 8(c) shows that the nose for the 5\% transformed fraction curve is located around $800^{\circ} \mathrm{C}$, in good agreement with the results for a similar composition alloy. ${ }^{19)}$ The precipitation nose temperature may indicate the maximum amount and the most sensitive embrittlement. In the present work, however, the maximum of volume fraction and the lowest impact energy was found to have occurred after the isothermal ageing at $700^{\circ} \mathrm{C}$. It can be seen that the TTT curves were in abnormal C-types, with "bulges" around $700^{\circ} \mathrm{C}$ when the transformed fraction was more than $5 \%$. Taking the Thermo-Calc simulation and TEM analysis into consideration, the TTT curves may result from the overlapping of nitrides and carbides.

The as-annealed sample, which was processed to have almost equivalent volume fractions of ferrite and austenite and contained no precipitates, exhibited ductile characteristic with a dimple rupture morphology after impact testing at room temperature. With increasing the isothermal ageing time, as shown in Figs. 8(a) and 10(a), the increase of precipitated fraction resulted in the drastic drop of impact energy. After having been aged for $120 \mathrm{~min}$, the nucleation of precipitates became to be difficult and the impact energy changed little with increasing ageing time. Grain boundary precipitates were believed to be facilitated to the nucleation and coalescence of micro-voids by causing inhomogeneous deformation and deteriorating grain boundary binding force. ${ }^{40)}$ Subjected to shear stress, grains can be easily torn apart along their boundaries due to the coalesced microvoids to form the river-like intra-granular facets, Fig. 11(b), which leads to embrittlement in the steel.

\section{Conclusion}

(1) $\mathrm{Cr}_{2} \mathrm{~N}$-type nitrides were formed as the main product of precipitates, together with small amount of $\mathrm{Cr}_{23} \mathrm{C}_{6}$-type carbides. Increase of $\mathrm{N}$ content and decrease $\mathrm{Cr}$ and $\mathrm{Mo}$ contents in the steel had led to the absence of $\sigma$-phase.

(2) Due to the solid solution strengthening by interstitial atoms, the hardness value of austenite was higher than that of ferrite. With increasing isothermal ageing times, precipitates at $\delta / \gamma$ interface preferentially nucleated and grew toward $\delta$ phase. The $\delta / \gamma$ interface migrated from the precipitate particles into $\delta$ phase, leaving the precipitates behind along the original interfaces, which could increase the size of the secondary austenite phase and decrease the hardness values of both austenite and ferrite.

(3) The measured nono-hardness in secondary austenite increased from $3.20 \mathrm{GPa}$ at the original interface to $3.75 \mathrm{GPa}$ at the newly formed interface between $\delta$ and $\gamma$.

(4) The kinetics for the formation of precipitates obeyed JMAK-type law, and the TTT curves may result from the overlapping of nitrides and carbides.

(5) When $2 \%$ secondary phases were precipitated during ageing, the impact energy was measured to be reduced by about $59 \%$ as compared to the as-annealed sample, indicating that formation of secondary phases can result in dramatic decrease of steel toughness.

\section{Acknowledgement}

The authors thank the support by the National Natural Science Foundation of China with contracts of 50734002 together with Baosteel Co.

\section{REFERENCES}

1) J. Charles: Duplex Stainless Steels '94, Proc. Conf., TWI, Glasgow, England, (1994), K1.

2) J. K. L. Lai, K. W. Wong and D. J. Li: Mater. Sci. Eng. A, 203 (1995), 356.

3) H. Sieurin, R. Sandstrom and E. M. Westin: Metall. Mater. Trans. A, 37 (2006), 2975.

4) M. Pohl, O. Storz and T. Glogowski: Mater. Charact., 58 (2007), 65.

5) S. B. Kim, K. W. Paik and Y. G. Kim: Mater. Sci. Eng. A, 247 (1998), 67.

6) M. Martins and L. R. N. Forti: Mater. Charact., 59 (2008), 162.

7) M. A. Dominguez-Aguila and R. C. Newman: Corros. Sci., 48 (2006), 2560.

8) Y. S. Ahn and J. P. Kang: Mater. Sci. Technol., 16 (2000), 382.

9) I. Calliari, M. Zanesco and E. Ramous: J. Mater. Sci., 41 (2006), 7643.

10) T. H. Chen, K. L. Weng and J. R. Yang: Mater. Sci. Eng. A, 338 (2002), 259.

11) Y. J. Kim, O. Ugurlu, C. Jiang, B. Gleeson and L. S. Chumbley: Metall. Mater. Trans. A, 38 (2007), 203.

12) Y. J. Kim, L. S. Chumbley and B. Gleeson: Metall. Mater. Trans. A, 35 (2004), 3377.

13) C. S. Huang and C. C. Shih: Mater. Sci. Eng. A, 402 (2005), 66.

14) W. Zhang, L. Z. Jiang. J. C. Hu and H. M. Song: Mater. Charact., 60 (2009), 50.

15) J. Charles: Steel Res. Int., 79 (2008), 455.

16) M. Lijias, P. Johansson, H. P. Liu and C. O. A. Ollsson: Steel Res. Int. 79 (2008), 466.

17) J. W. Christian: The Theory of Transformations in Metals and Alloys Part I, 2nd ed., Pergamon, Oxford, United Kingdom, (1975), 525.

18) J. U. Toor, P. J. Hyun and H. S. Kwon: Corros. Sci., 50 (2008), 404.

19) I. Calliari, K. Brunelli, M. Zanellato and E. Ramous: J. Mater. Sci., 44 (2009), 3764

20) K. H. Lo, C. H. Shek and J. K. L. Lai: Mater. Sci. Eng. R, 65 (2009) 
ISIJ International, Vol. 50 (2010), No. 2

39.

21) R. Merello, F. J. Botana, J. Botella, M. V. Matres and M. Marcos Corros. Sci., 45 (2003) 909.

22) M. L. Rudy and R. A. Huggins: Trans. Metall. Soc. AIME, 236 (1966), 1662

23) Yu. N. Petrov, V. G. Gavriljuk, H. Berns and Ch. Escher: Scr. Mater., 40 (1999), 669

24) V. G. Gavriljuk and H. Berns: High Nitrogen Steels, Springer-Verlag, Berlin, (1999), 378

25) T. Sourmail: Mater. Sci. Technol., 17 (2001), 1.

26) A. F. Padilha and P. R. Rios: ISIJ Int., 42 (2002), 325.

27) T. H. Chen and J. R. Yang: Mater. Sci. Eng. A, 338 (2002), 166

28) A. J. Ramirez, J. C. Lippold and S. D. Brandi: Metall. Mater. Trans. A, 34 (2003), 1575.

29) T. Amadou, A. Ben Rhouma, H. Sidhom, C. Braham and J. Ledion: Metall. Mater. Trans. A, 31 (2000), 2015.

30) C. S. Tedmon and D. A. Vermilyea: Metall. Mater. Trans. B, 1 (1970), 2043.

31) K. M. Lee, H. S. Cho and D. C. Choi: J. Alloy. Compd., 285 (1999),
156.

32) A. Weisbrodt-Reisch, M. Brummer, B. Hadler, B. Wolbank and E. A. Werner: Mater. Sci. Eng. A, 416 2006), 1.

$33)$ R. A. Perren, T. Suter, C. Solenthaler, G. Gullo, P. J. Uggowitzer, H. Bohni and M. O. Speidel: Corros. Sci., 43 (2001), 727.

34) Y. H. Jang, J. Son, S. Kim, J. Lee and B. Choi: Mater. Trans. A, 35 (2004), 3431

35) Y. H. Jang, J. Son, S. Kim, J. Lee and B. Choi: Metall. Mater. Trans. A, 36 (2005), 1229.

36) J. Wang, P. J. Uggowitzer, R. Magdowski and M. O. Speidel: Scr. Mater, 40 (1999), 123.

37) F. Vanderschaeve, R. Taillard and J. Foct: J. Mater. Sci., 30 (1995), 6035.

38) Z. Z. Yuan, Q. X. Dai, X. N. Cheng and K. M. Chen: Mater. Charact., 58 (2007), 87.

39) J. W. Elmer, T. A. Palmer and E. D. Specht: Metall. Mater. Trans. A, 38 (2007), 464.

40) T. S. Srivatsan, G. Guruprasad and V. K. Vasudevan: Mater. Des., 29 (2008), 742. 